\title{
Finite element analysis and parametric study of EWECS composite columns with double $\mathrm{H}$-shaped steel
}

\author{
Fauzan $^{1, *}$, Ruddy Kurniawan ${ }^{1}$, and Zev Al Jauhari ${ }^{2}$ \\ ${ }^{1}$ Civil Engineering Department, Andalas University, 25163 Limau Manis, Padang, Indonesia \\ ${ }^{2}$ Civil Engineering Department, Bengkalis State Polythecnic, 28711 Sungai Alam, Indonesia
}

\begin{abstract}
The behavior of composite column that consists of an exterior wood panel with concrete encased steel (CES) core, hereafter referred to as Engineering Wood Encased Concrete-Steel (EWECS) composite columns, is investigated. Nonlinear analysis is done by using finite element software, ANSYS APDL, to study the seismic performance of the columns. Verification of the finite element modeling is done by comparing and corresponding experimental result that reported by one of the authors, then it is used as a reference for parametric study. The parameters in the parametric study are the use of fiber reinforced concrete (FRC), the use of Indonesian wood and the use of friction element. The results are presented in the form of hysteresis characteristics, failure mode, and principal stress distribution. It is demonstrated that the seismic performance of the EWECS composite columns can be accurately predicted by proposing finite element modeling. Obtained results from the parametric study show that various FRC, different wood, and the contact element influences the hysteresis loops and behavior of the columns. The flexural capacity of the columns is improved about $7-17 \%$ by adding steel fiber. In addition, the typical Indonesian wood (Matoa) enhances the flexural strength about 3.3\%. Moreover, the use of a friction element affects the seismic behavior significantly.
\end{abstract}

\section{Introduction}

The innovation of the composite column structure has been widely researched and developed. In some countries, wood materials have been very popularly used as structural elements. Many houses and buildings are made of wood because of their environmentally friendly material and historical value. However, many developed countries such as Japan have regulation to strictly limit the story number of the wooden building [1]. A new composite structure has been developed in Japan as a solution for this limitation called Engineering Wood Encased Concrete-Steel (EWECS) composite structure. This composite structure consists of EWECS columns and EWES beams [2]. Fig. 1 shows the EWECS composite structure scheme for medium-rise buildings, such as apartments and offices.

The EWECS column is a new composite column, consisting of a steel encased concrete (CES) core covered by the wood panel, as shown in Fig. 2. Economic and structural advantages can be realized in this composite column. The concrete serves to withstand the local buckling of steel and increase the ductility of the structure [2].

The use of wood panel on this structure has several benefits. During construction, wood panel serves as a formwork of the column, which will reduce the construction costs. In addition, the woody panel can improve the behavior of structures on the column through its action of confining the CES cores and resisting to bending moments, shear, and buckling. This advantage makes EWECS columns applicable to the actual structure as an alternative to the SRC column, which has a weakness because it is difficult in the construction process [3].

Some experimental studies on the seismic performance of EWECS composite columns subjected to combined constant axial load and cyclic lateral load as a seismic simulation have been conducted by one of the authors in Japan [2-3]. Basically, an experimental study is ideal for studying behavior and structural failure. However, experimental studies take time and costly. In addition, the experimental study also requires adequate facilities, space, setting, and labour. If it is done correctly, finite element (FE) analysis is a powerful tool that can be an attractive alternative as a substitute and validate for experimental testing. This underlies the authors for developing finite element models using FEM-based software ANSYS APDL v14 [4]. The FE analysis software has been proved to enable the engineer perform multiple tasks, building computer models of the structural elements, applying loads and studying structural responses like the stress levels [5].

Models are developed by taking into account the nonlinear materials response. The FE analysis results are verified with the test results conducted by one of the authors [3]. Moreover, parametric studies were carried out with parameters such as the use of Fiber-reinforced

Corresponding author: fauzan@,ft.unand.ac.id, fauzanrn@,yahoo.com 
Concrete (FRC), the use of Indonesian woods, and the use of friction element between wood and concrete. The influence of these parameters on the performance of EWECS composite columns will be discussed.

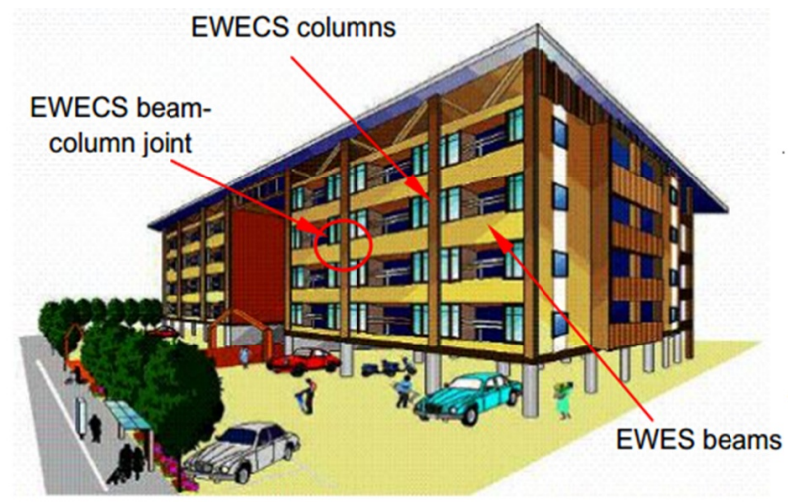

Fig. 1. EWECS composite structural system [2].

\subsection{The geometry of 3D model}

In this analysis, square size composite column was considered based on the experimental program, as described in Fig. 2. In all models, the column crosssections are $400 \times 400 \mathrm{~mm}^{2}$ with the column height of $1600 \mathrm{~mm}$. The height to depth ratio of the column is 4.0 . Double-H-shaped cross steels of $300 \times 150 \times 6.5 \times 9 \mathrm{~mm}$ were used as the encased steel of the column.

The dimensions and geometrical configuration of the test specimen are used to construct the finite element model. In order to get the high accuracy of the results with reasonable computational time, the mesh size was carefully determined. The aspect ratio of the solid elements, which is used in this analysis, was kept in the range between 1 and 4 . The model was discretized to obtain the most accurate results in with lowest computing time. The total numbers of element used are 5095 elements. In this analysis, the material was considered as non-linear behavior material [6].

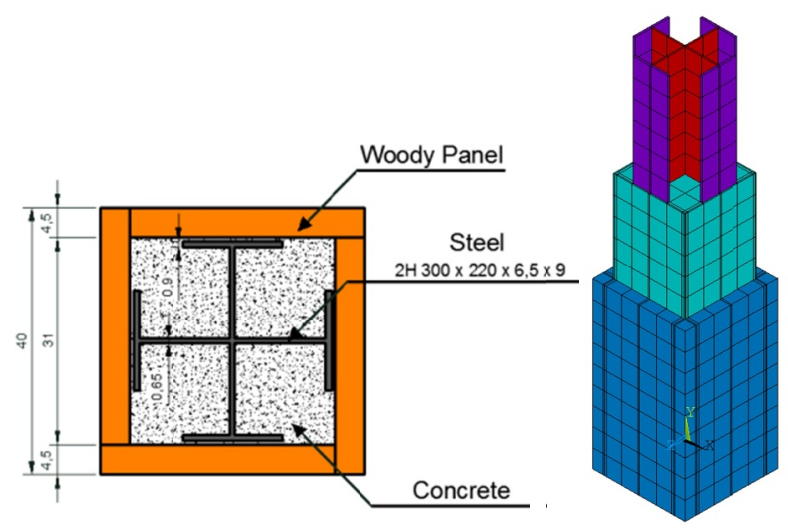

Fig. 2. Detail of test specimen and 3D model view of EWECS columns [4].

\subsection{Properties of material}

\subsubsection{Concrete}

The maximum compressive strength of concrete at failure was $35 \mathrm{MPa}$ with an ultimate strain of 0.0025 . The concrete Poison's ratio was taken 0.2 . The concrete material in compression was modelled as a multi-linear isotropic stress-strain relationship, which is developed by Saenz [7], using equations (1) - (3).

$f=E_{\mathrm{c}} * \varepsilon /\left[1+\left(\varepsilon / \varepsilon_{0}\right)^{2}\right]$

$\varepsilon_{0}=2 * f^{\prime}{ }_{c} / E_{c}$

$E_{c}=f / \varepsilon$

where:

$f=$ stress at any strain $\varepsilon, \mathrm{MPa}$

$\varepsilon=$ strain at stress $f$

$\varepsilon_{0}=$ strain at the ultimate compressive strength $f^{\prime}{ }_{c}$

Figs. 3 - 4 show the constitutive model of the concrete in compression and tension, respectively. The tension stiffening factor $\left(\mathrm{T}_{c}\right)$ was assumed 0.6 in this study. A descending line is used to model this behavior, as shown in Fig. 4. The strain value, $\varepsilon^{*}\left(6 \mathrm{x} \varepsilon_{\mathrm{t}}{ }^{\prime}\right)$ at zero tension stiffening stress is $\varepsilon^{*}=0.002 . E_{c}$ and $E_{t}$ are the modulus of elasticity of tensile concrete between zero to fracture strain and fracture strain to $\varepsilon^{*}$, respectively. $f_{t}$ is the maximum stress at fracture of concrete, which has corresponded to strain $\varepsilon_{t}$ '.

The shear transfer was varied between full and no shear transfers at the cracked section. In ANSYS, the amount of shear transfer across a crack (shear retention factors) is controlled by coefficients $\beta_{1}$ and $\beta_{2}$ for open and close cracks, respectively, with a range between 0 to 1. A shear transfer coefficient suggested by Al-Mahaidi [8] with a value of 0.75 and 0.9 for $\beta_{1}$ and $\beta_{2}$, respectively, is included in the analysis. Five parameter model of William-Warnke is applied as the fracture criterion in the concrete model [9].

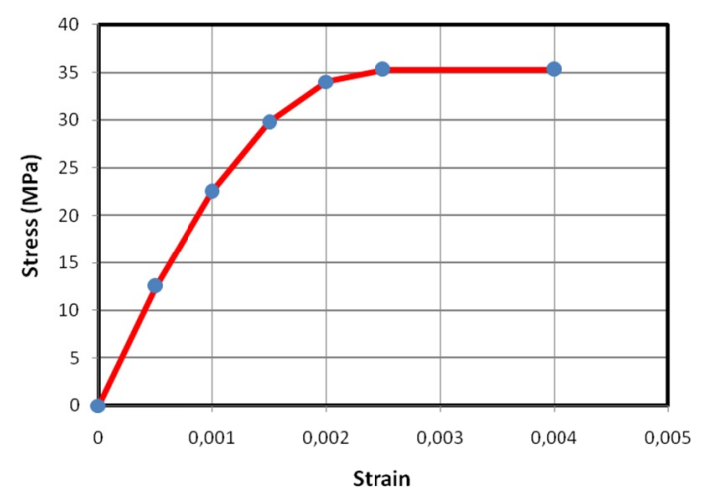

Fig. 3. Stress-strain relationship for concrete in compression. 


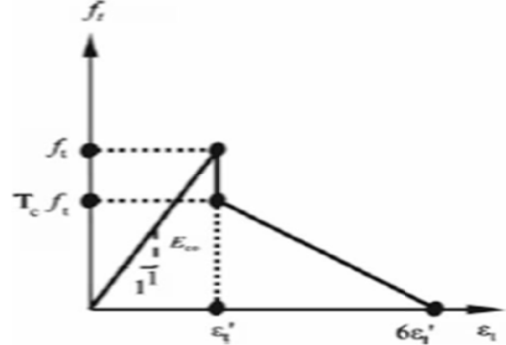

Fig. 4. Stress-strain relationship for concrete in tension

\subsubsection{Encased steel}

Fig. 5 shows the constitutive model of encased steel (bilinear model), which simulates the steel material response in this analysis. The initial stage is the linear elastic condition, which can be calculated using the equation (4):

$E_{s}=f_{y} / \varepsilon_{y}$

Where $\mathrm{E}_{\mathrm{s}}$ is equal to $200000 \mathrm{MPa}$. The yield strength $\left(f_{y}\right)$ of encased steel for flange and web is 412.5 and 453 $\mathrm{MPa}$, respectively. In this constitutive model, Von Mises yield criterion is applied.

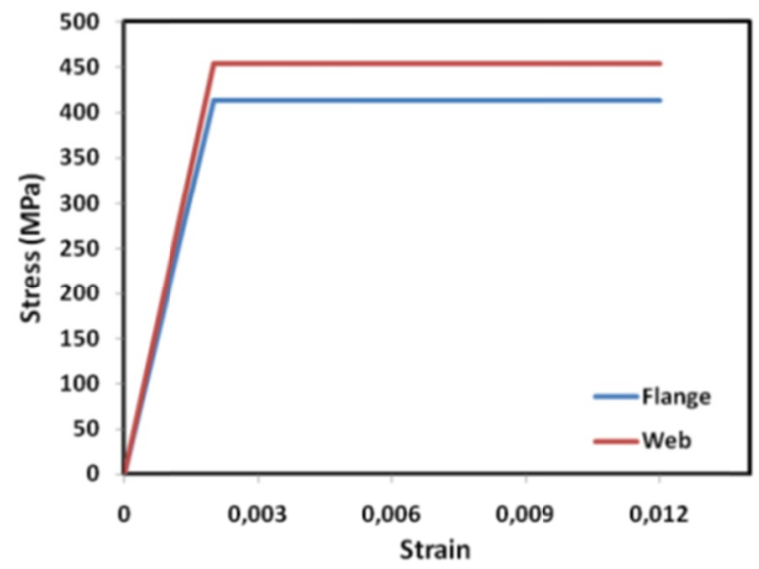

Fig. 5. Constitutive model for encased steel.

\subsubsection{Wood panel}

In this work, the properties of the wood panel were obtained from the material test. The ultimate compressive strength is $36.5 \mathrm{MPa}$ with an elasticity modulus of $10500 \mathrm{MPa}$. The data from the experiment were used in the finite element analysis. In this model, the force is assumed to be applied in the parallel direction to the annual growth ring of the wood, so that, some existing concrete data were built for wood characteristics [10]. The slightly reduced of the real wood constitutive model about $5 \%$ is applied in the finite element model, as seen in Fig. 6.

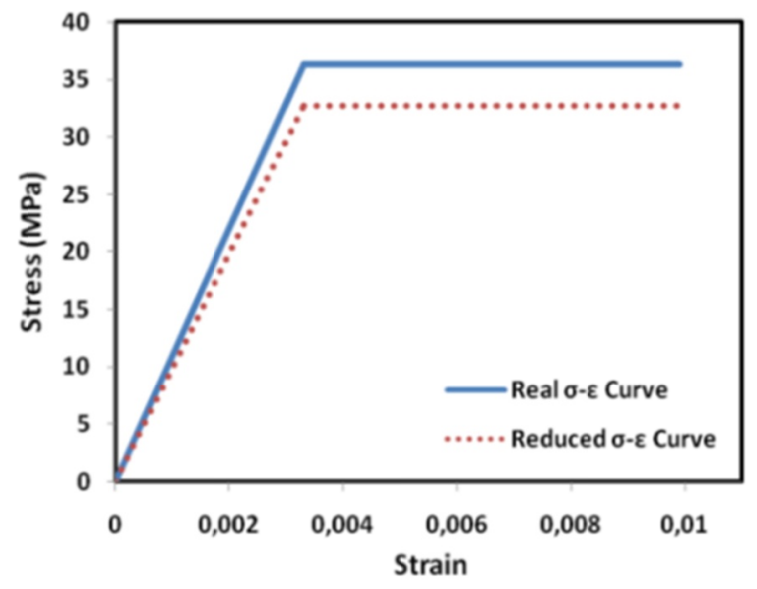

Fig. 6. Constitutive model for wood panel.

Considering the lower tensile strength in the direction perpendicular to the wood grain and also there is no bond connection between wood panel and concrete core, the ultimate tensile strength is taken as $5 \mathrm{MPa}$. The coefficient of modified shear transfer $\left(\beta_{c}\right)$ is 0.35 [8]. Also, the model of William-Wranke [9] is adopted for the fracture criterion of wood material characteristics.

\subsection{Element type}

There are two types of elements used to model the materials in the composite column, that are the SOLID65 element for concrete and the SOLID185 element for steel and wood, which is $3 \mathrm{D}$ hexahedral elements with eight nodes. There are 3 translational DOF at each node in the nodal $x, y$, and $z$ directions, as shown in Fig. 7 [4].

In this analysis, a perfect bond was assumed for the steel - concrete interface [11], whereas the wood panel - concrete interface was assumed as unbounded connection, which is modeled by decreasing the wood ultimate stress [12].
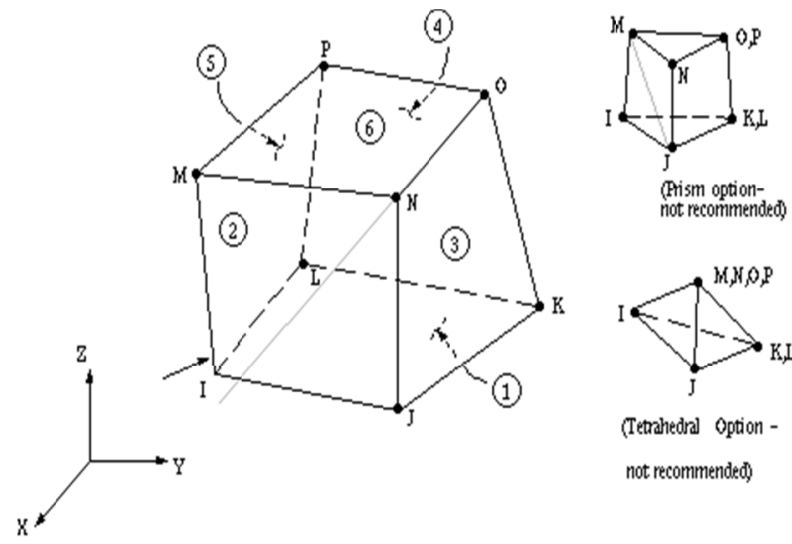

(Tetrahedral Option -

not recommended)

Fig. 7. Solid65 and Solid185 ANSYS elements [4]. 


\subsection{Boundary conditions}

The boundary conditions in the finite element model were modeled to simulate the test conditions (Fig. 8). The constant axial and cyclic lateral loads were applied on EWECS column by fixing the bottom end against the movement, while the load was applied at the upper end.

The bottom end of the simulated specimen was fixed against all DOF. Simultaneously, the upper end restrained against all DOF except the one in Y- direction, as shown in Fig. 9. The lateral cyclic load was applied to the upper end using controlled displacement and the strength of column was measured using a reference point at the lower end [13]. In addition, the base shear and top displacement are monitored.

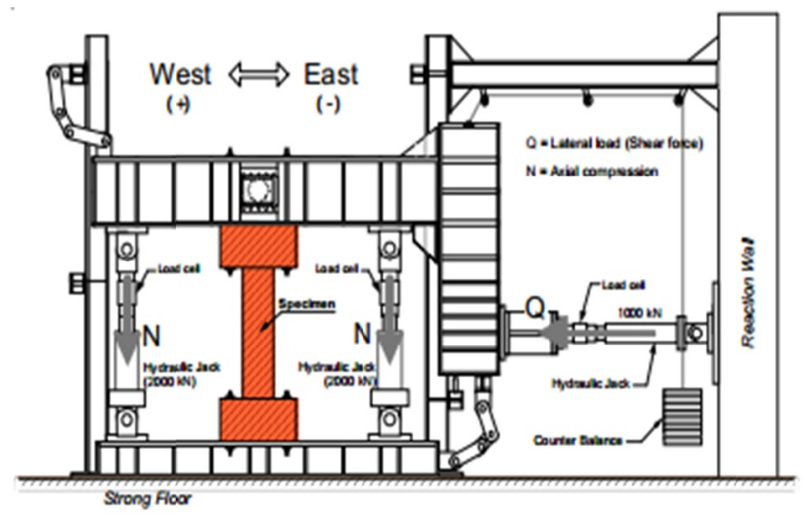

Fig. 8. Schematic view of test setup.

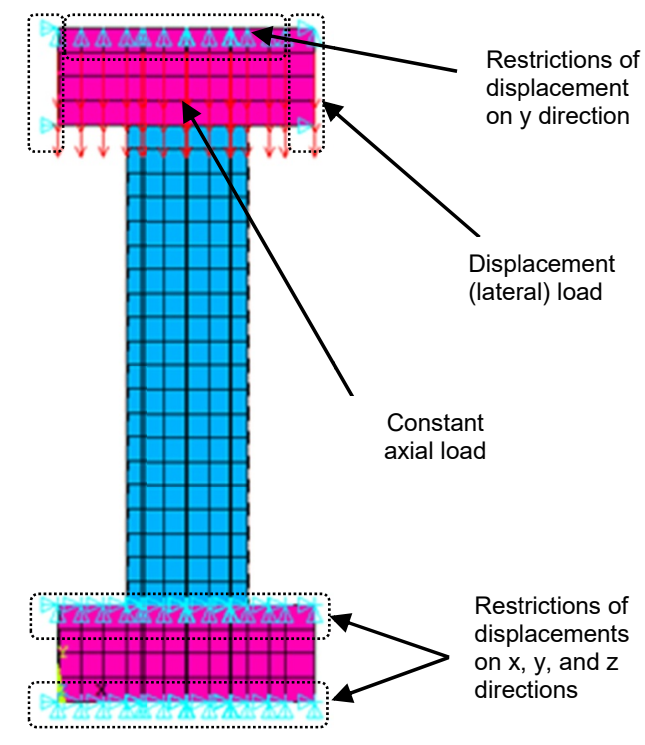

Fig. 9. Boundary conditions and loads in the FE model.

\subsection{Loads}

The combined constant axial load and cyclic lateral load were applied to EWECS column. The FE modeling procedure for analyzing EWECS columns subjected to bidirectional cyclic loads are presented in this paper. The constant compressive loading in axial direction is applied on top of the column, approximately $770 \mathrm{kN}$.
The cyclic lateral load is simulated by applying the displacement control scheme rather than direct loading to generate cyclic behavior of the column. A step by step increment of lateral loading cycles are controlled by story drift angle, $\mathrm{R}$, which is defined as the ratio of lateral displacement to the column height, $\delta / \mathrm{h}$. Fig. 10 shows the loading history of FE model which is similar to the experimental work.

\subsection{Nonlinear solution}

In this analysis, the load step size increments were controlled using the automatic time stepping option. Newton-Rapson equilibrium iterations are updated the model stiffness in ANSYS [14]. The tolerance related to this convergence criterion and the incremental of load step is varied in order to solve potential numerical problems. However, the solution does not converge for the set of parameters considered, as far as load step size and convergence criterion are concerned. The convergence tolerance limits of $10 \%$ are adopted for the displacement checking criterion to get the equilibrium iterations convergence.

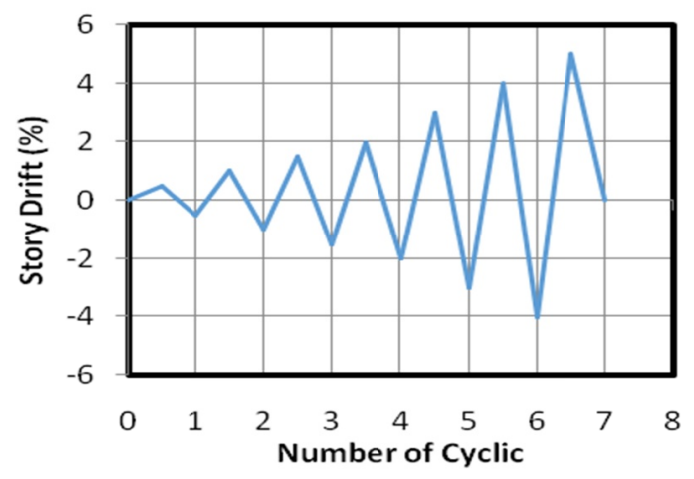

Fig. 10. Lateral cyclic loading history.

\section{Result and discussions}

\subsection{Validation of proposed model}

The proposed model produced the outputs about the behavior of the EWECS composite columns such as the load-displacement curve, the failure mode, and the principal stress distribution. The results of the FE model is verified against the experimental data [3]. The hysteresis curves provide the required information on the load-deformation paths of the members for analysis.

The experimental hysteresis loop (shear force vs story drift) for the EWECS column is compared to those obtained from the numerical analysis, as shown in Fig. 11. As seen in the figure, the maximum shear force from FE analysis was slightly higher (around 9\%) than the test data. In addition, the energy dissipation of the finite element model in the last story drift was less than that of in the experimental results. The different between FE analysis results and experimental data in maximum shear force at each loading stage is about $8.4 \%$. 


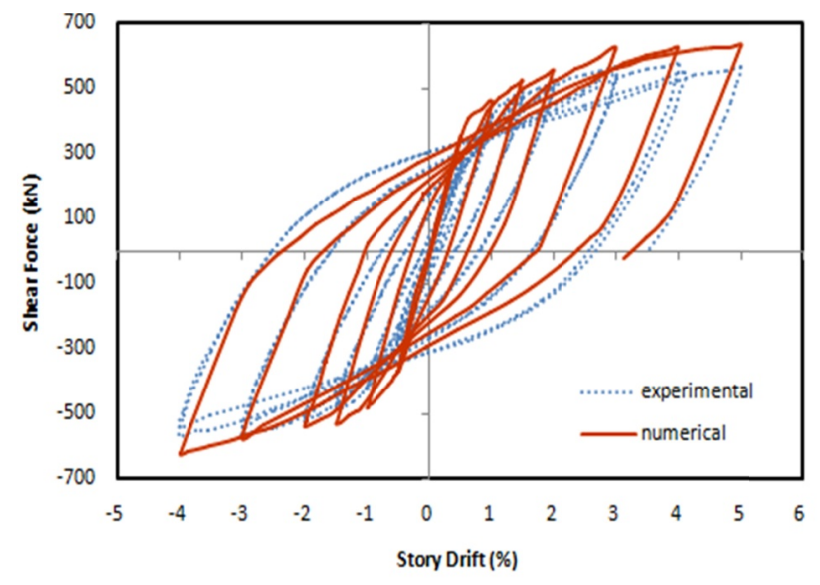

Fig. 11. Comparison of hysteresis loop of EWECS column between test and numerical results.

\subsection{Parametric study of EWECS column}

From the above numerical analysis of EWECS column, the FE model can provide an accurate prediction for its seismic behavior, which has been compared to the experimental program. In order to know more about the behavior of EWECS composite columns under seismic loading, a parametric study was carried out to identify the influence of the possible material used in the composite columns such as the use of Fiber Reinforced Concrete (FRC) for the concrete core and the use of Indonesian wood. In addition, the effect of applying friction element between wood and concrete was used as a parameter in this study. These parameters were chosen because of the importance of the material in structural resistance, and it can improve seismic behavior without significantly changing the column dimensions. Table 1 shows the different values of each parameter for the parametric study. In this parametric study, the numerical model that has been validated with the test data referred to the reference model [15].

Table 1. Parameters for parametric study.

\begin{tabular}{|c|l|}
\hline Parameter & \multicolumn{1}{|c|}{ Type } \\
\hline The use of FRC & $\begin{array}{l}\text { (a) PVA fiber RF4000 2\% } \\
\text { (b) SS fiber (F430D) } 2 \%\end{array}$ \\
\hline $\begin{array}{c}\text { The use of } \\
\text { Indonesian wood }\end{array}$ & $\begin{array}{l}\text { (a) Kapur wood } \\
\text { (b) Matoa wood }\end{array}$ \\
\hline $\begin{array}{c}\text { The use of friction } \\
\text { element }\end{array}$ & Conta and Targe Element ANSYS \\
\hline
\end{tabular}

\subsubsection{The use of FRC}

Fiber reinforced concrete (FRC) is concrete containing fibrous material such as steel fibers and synthetic fibers, which improves its mechanical properties. FRC has small distinct fibers that are homogeneously dispersed and distributed randomly in the concrete mix. The use of fibers in concrete will increase the tensile and flexural strengths of the concrete. In addition, the fiber contributes to control the concrete crack opening by giving the higher bonding on the concrete [16].

In the first phase parametric analysis, the EWECS column models were built by name Reference (R), VF1, and VF2 for the EWECS using normal concrete model, the model use Polyvinyl Acetate (PVA) fiber RF4000 $2 \%$, and the models use stainless steel (SS) fiber F340D $2 \%$, respectively. The dimension of the steel and wood details are similar to that of EWECS columns model. The difference was only the concrete used. Mechanical properties of FRC uses PVA fiber RF4000 2\% obtained from materials test at the age of 28 days are respectively 39.6 $\mathrm{MPa}$ and $7.97 \mathrm{MPa}$ for compressive and tensile strengths, while the SS fiber F340D 2\% is $43.2 \mathrm{MPa}$ and 8.74 MPa. The features and related data of other structural elements in numerical simulations of FRC remain constant and similar to normal concrete.

The features of other structural elements in numerical simulations of parametric analysis remain constant. The related data for parametric analysis are similar to reference model analysis. Fig. 12 and Table 2 show the comparison of hysteresis loops and seismic performance (stiffness, strength, and energy dissipation) of EWECS columns with respectively having variation at the compressive strength of concrete.

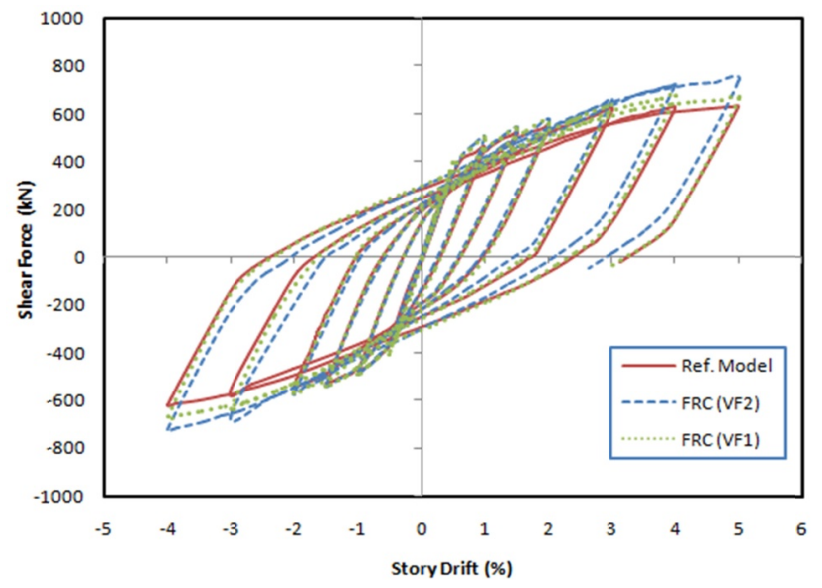

Fig. 12. Comparison of hysteresis loop of EWECS columns with varying types of FRC.

Table 2. Results of parametric study of EWECS Columns with varying types of FRC.

\begin{tabular}{|c|c|c|c|}
\hline Model & $\begin{array}{c}\text { Max. Strength } \\
(\mathbf{k N})\end{array}$ & $\begin{array}{c}\text { Stiffness } \\
(\mathbf{k N} / \mathbf{m m})\end{array}$ & $\begin{array}{c}\text { Energy } \\
\text { Diss. (kJ) }\end{array}$ \\
\hline Ref. & 630 & 8,68 & 165,1 \\
\hline VF1 & 675 & 9,27 & 172,1 \\
\hline VF2 & 740,3 & 10,14 & 181 \\
\hline
\end{tabular}

The model with FRC uses PVA fiber RF4000 2\% (Model VF1) displays a stiffness of $6.79 \%$ greater than Model R, whereas the model with FRC uses SS fiber F340D 2\% (Model VF2) displays a 16.82\% greater than Model R. The use of FRC on concrete lead to a higher 
energy dissipation around 4-9\%. Model VF1 displays a $7 \%$ increase in maximum flexural capacity, while Model VF2 displays a $17 \%$ increase in maximum flexural capacity to resist the lateral load. These results indicate that the use of FRC affects to the seismic performance of the EWECS column.

In the experimental data, the crack of wood and significant damage to the column occurred after $\mathrm{R}=3 \%$, which was similar behavior obtained in the FE Model of the parametric study. The stress in each material is analysed, which was validated by the FE model. A principal strain of 0.002 has been reached in the encased steel of Model VF1 at story drift $0.54 \%$, as shown in Fig. 13. The elastic modulus of the steel is $200000 \mathrm{MPa}$, with the yield stress of $412 \mathrm{MPa}$. The minimum principal stress distribution in the FE model illustrates that first crack in the concrete starts at $\mathrm{R}$ of $0.3 \%$ in the strut zone, and propagate to the horizontal direction. The crushed concrete elements were observed in the top and bottom of the column, while the concentration of cracks was less in the middle of the column height, as shown in Fig. 14.
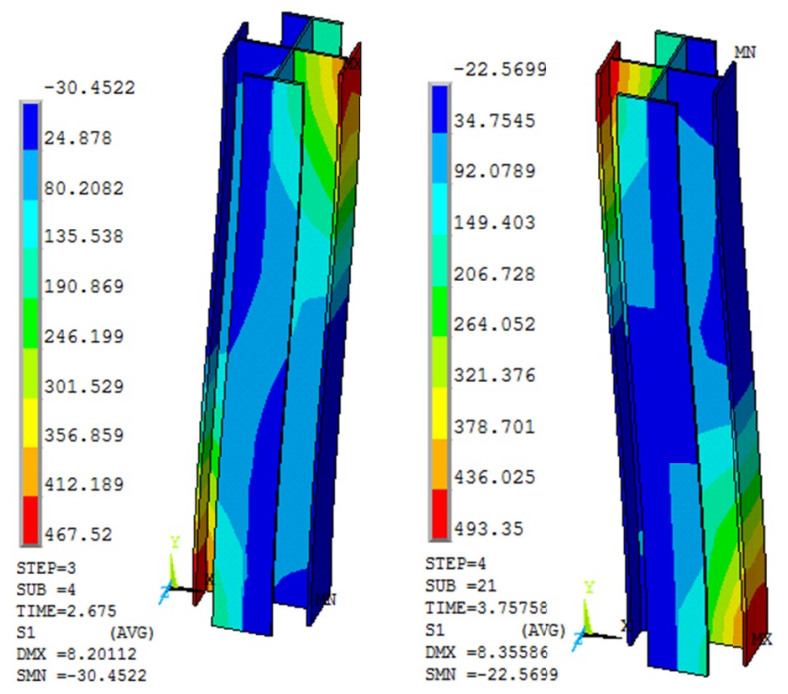

Fig. 13. First yield in the steel web.
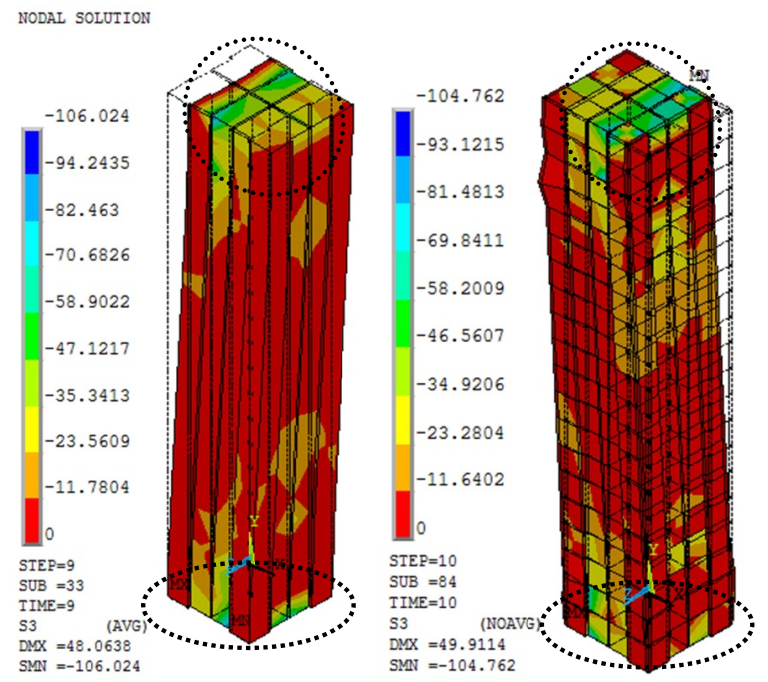

Fig. 14. Failure patterns in infill concrete (crush).

\subsubsection{The use of Indonesian wood}

The panel wood is the outermost component of the EWECS composite column that interacts with the concrete. It contributes to give the confinement of CES core to resist the bending moment and shear force. In addition, the wood panel contributes to prevent the column buckling. In these parametric studies, different types of Indonesian wood are used to investigate the effect of this parameter on the column behavior. The typical wood used in this parametric study are chosen by commonly used the wood as a structural component such as Kapur and Matoa. Table 3 shows the mechanical properties of the wood.

Fig. 15 presents the shear force versus story drift (hysteresis loop) of EWECS column with having variation in the type of wood panel. This curve illustrates the differences between the stiffness, strength, and energy dissipation of each model, as shown in Table 4.

Table 3. Properties of Indonesian woods.

\begin{tabular}{|c|c|c|}
\hline Properties & $\begin{array}{c}\text { Value of } \\
\text { Matoa }\end{array}$ & $\begin{array}{c}\text { Value of } \\
\text { Kapur }\end{array}$ \\
\hline 1. $\mathrm{Ft}\left(\mathrm{kg} / \mathrm{cm}^{2}\right)$ & 1. 48 & 1. 50 \\
\hline 2. $\mathrm{Fc}\left(\mathrm{kg} / \mathrm{cm}^{2}\right)$ & 2. 628 & 2. 578 \\
\hline 3. $\operatorname{Ew}\left(\mathrm{kg} / \mathrm{cm}^{2}\right)$ & 3. 172000 & 3. 143000 \\
\hline 4. Poisson's Ratio & 4. 0,34 & 4. 0,33 \\
\hline
\end{tabular}

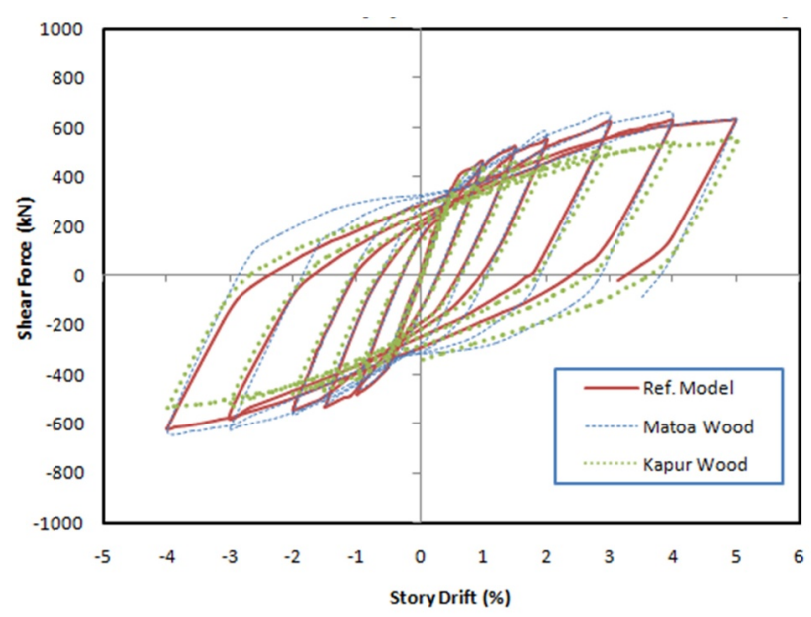

Fig. 15. Comparison of hysteresis loop of EWECS columns with varying types of Indonesian wood.

The model with Matoa wood shows the slightly higher stiffness (around 2\%) than Model R, whereas the model with Kapur wood displays an $11 \%$ smaller than Model R. The Matoa wood panel have an increase at the flexural capacity around $3.3 \%$ than the Model R. The percentage difference of energy dissipation in the columns by variating in the kind of wood around 13$16 \%$. The results of the simulations indicate that the type of wood panel influences the behavior of the EWECS column. 
Table 4. Results of parametric study of EWECS columns with varying types of Indonesian wood.

\begin{tabular}{|c|c|c|c|}
\hline Model & $\begin{array}{c}\text { Max. } \\
\text { Strength } \\
(\mathbf{k N})\end{array}$ & $\begin{array}{c}\text { Stiffness } \\
\mathbf{( k N / m m )}\end{array}$ & $\begin{array}{c}\text { Energy } \\
\text { Diss. (kJ) }\end{array}$ \\
\hline Ref & 630 & 8,68 & 165,1 \\
\hline Matoa & 650,9 & 8,91 & 192 \\
\hline Kapur & 541,1 & 7,69 & 143,2 \\
\hline
\end{tabular}

Fig. 16 shows the $1^{\text {st }}$ principal normal stress on both the Matoa wood and Kapur wood models. The stress is concentrated on the edge bottom and top of the wood, where sink (due to compression) and uplift (due to tensile) occur. These good comparative results indicate that the FE analysis is able to predict and simulate accurately the seismic performance of EWECS column, especially the ultimate strength of the composite column.
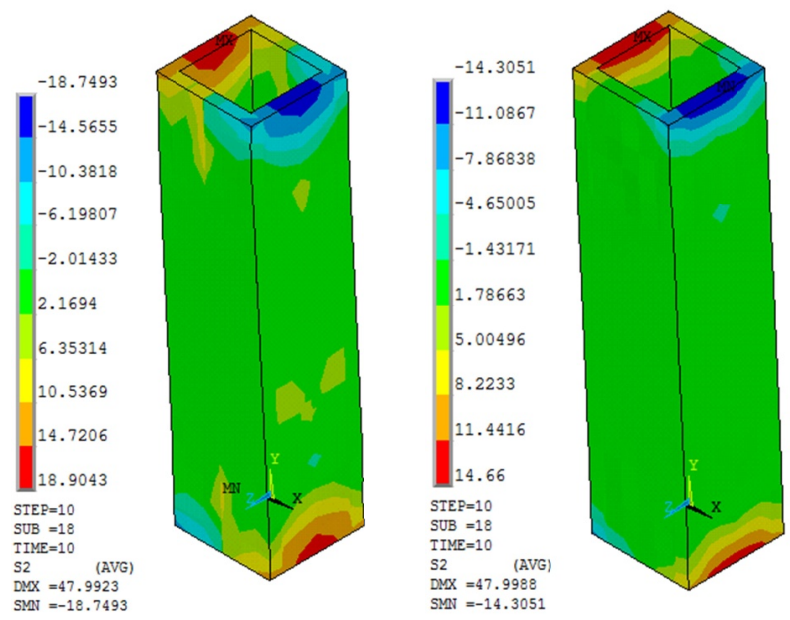

Fig. 16. The $1^{\text {st }}$ principal normal stress on both the Matoa wood and Kapur wood models.

\subsubsection{The use of friction element}

In this study, the use of friction element was analyzed to investigate the effect of the applied fiction element in seismic performance the EWECS columns. Two types of element, CONTA174 and TARGE170 were used for the contact between two difference and target surfaces. Surfaces with finer mesh were used as contact surface, whereas surfaces with coarser meshes were used as target surfaces. Fig. 17 shows the 8-node contact elements used in this analysis.

The standard unilateral contact behavior with normal sliding friction behavior is used in this analysis since there is sliding with contact closing and opening behavior between connection's surfaces [6]. The normal pressure in the FE analysis was set to zero if separation occurs between the surfaces in contact.

Fig. 18 shows the hysteresis loops of the FE model with and without friction element. As shown in the figure, the maximum lateral shear force of $730 \mathrm{kN}$ was obtained at last story drift 5\% for EWECS column with friction element, which was $16.3 \%$ higher than that of FE model without friction element (with assumption reduction the strength of wood). From the figure, it is clearly seen that the results of FE model using friction element are higher than the reference model in each loading stage with a different percentage of lateral shear force around $12.8 \%$.

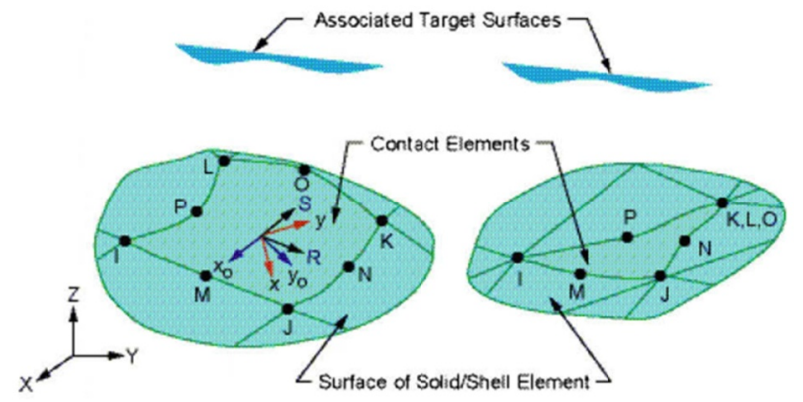

Fig. 17. Conta174 and Targe 170 ANSYS elements.

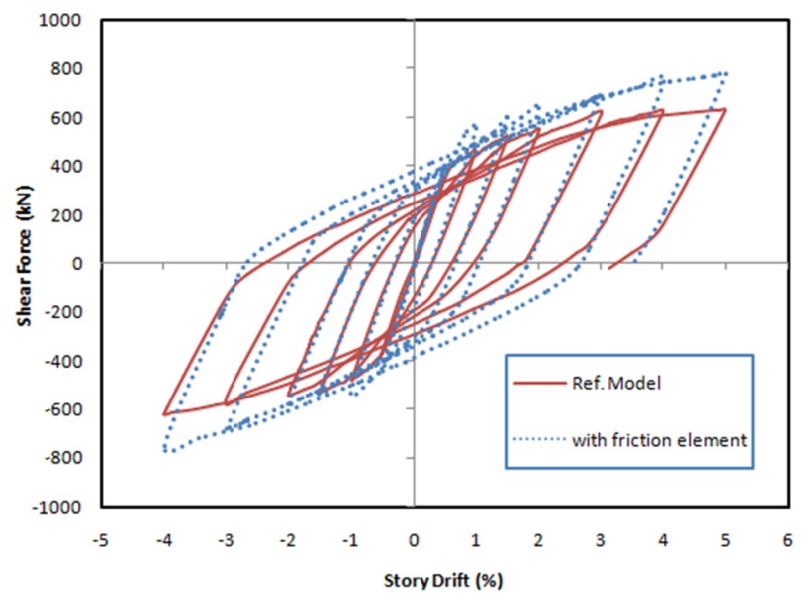

Fig. 18. Comparison of hysteresis loop of EWECS columns between models with and without friction element.

\section{Conclusion}

A nonlinear FE analysis of the seismic behavior of EWECS composite column has been conducted in this study. The results of the FE analysis were compared to the experimental data. A parametric study of the EWECS column was performed to explore the effects of other structural parameters that are the effect of different materials such as FRC and Indonesian woods, and the effect of friction element between wood and concrete.

In general, the hysteresis loop and failure mode of the FE model of EWECS column sufficiently portrays the behavior of the test column both in elastic and plastic ranges. The comparisons between the analytical prédictions and experimental data show that the FE model enables to validate the behavior of the EWECS columns. The results of the parametric analysis demonstrate that the type of wood has a little influence to the hysteresis characteristics (behavior) of EWECS columns, in which the Matoa wood increases the flexural capacity by around $3.3 \%$. Also, the uses of FRC 
increases the flexural capacity of the column up to $17 \%$. The use of friction element affects the seismic behavior significantly, with the difference of flexural strength about $16.3 \%$.

\section{References}

1. Ministry of Construction, Stipulation of criteria with respect to structural calculations performed to confirm the safety from the point of view of structural capacity of wooden columns. Building Standard Law of Japan Notification No. 1349, May 23, 2000.

2. Fauzan, H. Kuramoto, and K.H. Kim, "Seismic performance of composite EWECS columns using single H-steel", Proceeding of JCI 27(2), 2005, pp. 307-312.

3. H. Kuramoto, and Fauzan, "Feasibility study on engineering wood encased concrete-steel composite columns", Proceeding $11^{\text {th }}$ Int. Colloquium on Structural and Geotechnical Engineering (1 $1^{\text {th }}$ ICSGE), Ain Shams University, Cairo, Egypt, 2005.

4. ANSYS Version 14. 2010. User's and theory reference manual.

5. M. M. A. Kadhim, "Nonlinear FE analysis of reinforced H.S. concrete continuous beam strengthened with CFRP sheet", Proceeding of the International Conference on Advanced Science, Engineering and Information Technology, 2011, pp. $597-601$.

6. M. K. Hassan, M. F. M. Zain, and M. Jamil, "Finite element analysis of the effect of crack depth and crack opening on the girder", Proceeding of the International Conference on Advanced Science, Engineering and Information Technology, 2011, pp. $646-651$.

7. L. P. Saenz, "Discussion of equation for the stressstrain curve for concrete" Journal American Concrete Institute, vol. 61(9), pp. 1229-1235, 1964.

8. R. S. H. Al-Mahaidi, "Nonlinear finite element analysis of reinforced concrete deep members", Rep. No. 79(1), Department of Structural Engineering, Cornell University, Ithaca, New York. 1979.

9. K. L. Willam, and E. P. Warnke, "Constitutive model for the triaxial behavior of concrete", Proc. International Association for Bridge and Structural Engineering (IABSE), vol. 19, Zurich, Switzerland, 1975.

10. H. Kuramoto, B. Li, K. Meas, and Fauzan, "Experimental and analytical performance evaluation of engineering wood encased concretesteel beam-column joints", Journal of Structural Engineering ASCE, pp. 822-833, 2011.

11. A. Leskes, and S. Grambicka, "Theoretical and experimental studies on composite steel-concrete columns", Proc. Eng. Science direct, vol. 65, 2013, pp. 405-410.
12. Fauzan, and H. Kuramoto, "Seismic performance of EWECS composite columns in new hybrid structural system", Composite Construction in Steel and Concrete, vol. 6, pp. 263-275, 2011.

13. Y. R. Abbas, "Nonlinear finite element analysis to the circular CFST stub columns", $11^{\text {th }}$ Int. Symposium on Plasticity and Impact Mechanics, Procedia Engineering, vol. 173, pp.1692-1699, 2017.

14. R. A. Hawileh, A. Rahman, and H. Tabatabai, "Nonlinier finite element analysis and modelling of a precast hybrid beam-column connection subjected to cyclic loads", Journal Applied Mathematical Modelling, vol. 34, pp. 2562-2583, 2010.

15. N. Marcela, and L. Ana, "Parametric study of composite beam-column connections using 3D finite element modeling", Journal Construction Steel Research, vol. 102, pp. 136-149, 2014.

16. Fauzan, Febrin A. I., Rio S., Nurhasan S., and Anisa P. M., "The effects of steel fibers extracted from waste tyre on concrete containing palm oil fuel ash", International Journal of GEOMATE, vol. 14(44), pp. 142-148, 2018. 